\title{
O corpo nas imagens da guerra colonial portuguesa: subjetividades em análise ${ }^{1}$
}

\author{
Clara Roldão Pinto Caldeira' \\ https://orcid.org/0000-0001-7643-0988 \\ I - Universidade Católica Portuguesa \\ Lisboa, Portugal
}

Resumo: Este artigo analisa a representação dos corpos em imagens fotográficas produzidas no contexto da Guerra Colonial Portuguesa, por militares portugueses, que os retratavam e também à população local. Partindo da ideia do corpo como elemento constituinte da subjetividade, estas imagens estabelecem-se como territórios de tensão e negociação das complexas identidades em causa. A análise terá em conta os regimes visuais dominantes que contextualizam estas fotografias, nomeadamente através de uma arqueologia do seu campo imagético, mobilizando o binômio retrato honorífico/retrato disciplinar. Consideram-se ainda as possibilidades de resistência às convenções representativas no espaço fotográfico, e os processos de performatividade hermenêutica que incluem também o espectador actual destas imagens, na articulação entre memória e fotografia.

Palavras-chave: guerra colonial portuguesa; representações do corpo; fotografia; Estudos Visuais.

Abstract: The body in the images of the Portuguese Colonial War: subjectivities under analysis This paper intends to analyze the representation of bodies in photographic images by the Portuguese military, representing themselves and local population, produced in the context of the Portuguese Colonial War. Starting with the idea of the body as a constituent element of subjectivity, these images present themselves as spaces of tension and negotiation of complex identities. The analysis will take into account the dominant visual regimes that contextualize these photos, namely through an archaeology of the imagetic field, mobilizing the binomial honorific portrait/disciplinary portrait. The possibilities of resistance to conventions of representation in the photographic space and the processes of hermeneutical performativity that also include the contemporary spectator of these images are also considered in the articulation between memory and photography.

Keywords: Portuguese colonial war; representations of the body; photography; Visual Studies.

1 Mantivemos a grafia de Portugal (nota do editor). 


\section{Introdução}

Este artigo resulta de uma investigação mais ampla sobre imagens fotográficas produzidas por combatentes portugueses da guerra colonial que opôs Portugal, então um estado imperial e autocrático, aos movimentos independentistas de três colónias africanas - Angola, Guiné e Moçambique - entre 1961 e 1974. Neste âmbito, analisar-se-ão em particular representações do corpo, partindo da sua importância enquanto elemento constitutivo da identidade e, por isso, em contexto de guerra, especialmente relevante a nível das políticas de representação. Tratando-se de um contexto colonial e de conflito, procurar-se-á nestas imagens analisar questões relativas a dinâmicas de poder, mas também de resistência e negociação. Consideramos fotografias de três álbuns particulares, de imagens produzidas entre 1963 e 1973. Destes arquivos selecionamos aquelas em que o corpo é um aspecto destacado, surgindo quase sempre isolado, pontualmente na companhia de outros. Que corpos são aqui retratados? Que dinâmicas relevam entre fotógrafo e fotografado? De que formas se inscrevem na imagem aspectos do conflito? Como interpelam hoje a memória deste acontecimento histórico?

\section{Imagens de uma viagem ao (des)conhecido}

A guerra colonial marca, para Portugal, a transição entre a ditadura e a democracia, culminando com as independências das colônias, uma transformação geopolítica tardia, mas que, genericamente, acompanha uma das maiores mudanças globais do século XX, a descolonização, em termos de relação entre nações e povos, suas dinâmicas de poder, valores e modos de estar associados dentro das sociedades.

O conflito, desenvolvido em três territórios, mobilizou cerca de 900 mil portugueses (PIMENTEL, 2011), entre militares de carreira e milicianos, que foram, com mais ou menos convicção, aqueles que constituiram a defesa do chamado terceiro império português em África nos quase quatorze anos de duração do conflito, criando uma situação transversal a toda a sociedade portuguesa, com um ou mais familiares embarcados.

A maioria dos mobilizados, sobretudo homens jovens, não tinha qualquer contato com território africano, tema relevante da propaganda nacional ${ }^{2}$ mas uma abstracção para a maioria daqueles que foram chamados a combater. Tornam-se assim sujeitos daquilo que Marie Louise Pratt, numa obra sobre literatura de viagem, designa por "zona de contacto", definido desta forma: "[...] o espaço de encontros coloniais, o espaço em que povos geográfica e historicamente apartados entram em contacto e estabelecem relações

2 "Portugal não é um país pequeno" foi um slogan que acompanhou a propaganda do Estado Novo sobre a questão colonial. A frase surgiu pela primeira vez inscrita num cartaz produzido para a Exposição Colonial Portuguesa que se realizou na cidade do Porto em 1934, e teve como comissário Henrique Galvão. A frase estava inscrita sobre um mapa que pretendia ilustrar a dimensão do império português, sobrepondo as áreas territoriais das colônias aos países europeus. (Matos, 2006, p.190). Imagem disponível para visualização aqui: https://www.researchgate.net/figure/Figura-2-Portugal-nao-e-um-pais-pequeno-fonte-Henrique-Galvao-1934C-Arquivo_fig1_272162619 Acesso em 2 dez. 2018 
continuadas, envolvendo normalmente condições de coerção, radical desigualdade e conflitualidade irascível" (PRATT, 1992, p.6). A autora esclarece que este conceito se aplica à co-presença de sujeitos antes apartados pelas suas circunstâncias históricas e geográficas, cujas trajetórias se intersectam, marcadas pelo imperativo da comunicação, interagindo de forma mutuamente influente.

As fotografias produzidas pelos militares portugueses, neste contexto, são um resultado desse encontro, durante a guerra, em que o corpo e a sua sobrevivência, mas também a sua representação, são aspectos centrais da experiência. Uma vez que os militares portugueses eram os portadores exclusivos da tecnologia fotográfica, é possível afirmar que se encontram, no campo representacional, desde logo numa posição de poder, sendo escassas as circunstâncias de contra representação. As imagens selecionadas mostram uma preocupação com o auto-retrato do integrante da tropa portuguesa mas também um olhar sobre a população local, em situações de aparente convivência pacífica, reportando-se, por exemplo, ao contato com civis em aldeias reinstaladas longe dos lugares de origem e vigiadas pelas autoridades militares portuguesas, uma prática que tinha o objetivo de impedir o apoio aos movimentos independentistas, acompanhada, porém, de uma retórica de ação social.

Neste corpus não encontramos imagens de violência, hostilidade ou confronto expressos. Na esteira de Marie Louise Pratt que, debruçando-se sobre literatura, recorre a termos fortemente visuais, identificamos a estratégia representacional definida como de "anti-conquista":

\begin{abstract}
Um segundo termo que utilizo com frequência no desenvolvimento que se segue é "anti-conquista", referindo-me às estratégias de representação pelas quais os burgueses europeus procuram afirmar a sua inocência, ao mesmo tempo que garantem a hegemonia europeia. O termo "anti-conquista" foi escolhido, de acordo com o meu argumento, porque em escritos de viagem e de explorações estas estratégias de inocência são constituídas em articulação com uma retórica colonial mais antiga de conquista associada à era absolutista. O principal protagonista da anti-conquista é uma personagem que por vezes designo por "o homem que vê", um rótulo claramente desagradável para o sujeito masculino europeu da paisagem discursiva europeia — aquele que com olhos imperiais displicentemente contempla e possui (PRATT, 1992, p.7).
\end{abstract}

O "homem que vê": aquele que tem uma máquina fotográfica, o militar português, olha o corpo de guerra, o seu e do outro.

É de assinalar a existência de uma retórica oficial sobre o conflito, que se joga também no campo da visualidade do corpo. Em 1961, os primeiros incidentes de contestação do regime colonial em Angola são amplamente divulgados pelo regime, com recurso a fotografias violentas de corpos esventrados, alvo de amputações e manipulações, resultado dos ataques de movimentos independentistas às fazendas brancas, numa clara instrumentalização política das imagens para justificar, em termos diplomáticos, a nível nacional e internacional, com exibição histórica na sede da ONU, o contraataque da metrópole que, no entanto, não é tornada visível (RAMOS, 2014). Ao longo 
do desenvolvimento do conflito, esta mensagem é suavizada. O regime evitava a confirmação de uma situação bélica declarada e o envio de tropas era, antes, divulgado na comunicação social portuguesa enquanto resposta às ações ditas terroristas, de inspiração comunista, com sede em países adjacentes às colônias, no âmbito do que a investigadora Tânia Alves caracteriza como uma "ficção informacional" (ALVES, 2016, p. 79). Este era um discurso fortemente ancorado na defesa da singularidade do colonialismo português, inspirada nas teses de Gilberto Freyre, promovido como mais benevolente do que qualquer outro, desejado e aceite pelas populações africanas e tradicionalmente assente em práticas de convívio inter-racial pacífico, integrador e unitário. Como afirma Cláudia Castelo, num estudo sobre o luso-tropicalismo e a ideologia colonial portuguesa:

O autor parte do pressuposto que essa unidade existe e que o português é o seu elemento fundador e aglutinador. As características do português, já analisadas em Casa-grande \& senzala - ausência de preconceito racial, apetência pela miscigenação, cristianismo fraternal - é que conferem coerência ao mundo por ele criado (CASTELO, 2011, p.33).

Um exemplo do investimento visual neste ideário é a ilustração de 1969 (figura 1), produzida por um militar português com experiência profissional gráfica, cooptado para o departamento de Ação Psicológica, órgão militar responsável pelas campanhas de sensibilização da população. Trata-se, literalmente, de uma corporização da mensagem propagandística, ao sintetizar no abraço entre um soldado e uma criança, ambos negros e brancos, o espírito de união inter-racial da nação pluricontinental, destinada à vitória (os braços unidos formam um V). O símbolo composto pela esfera armilar e escudo português na boina do soldado (presente na bandeira), o fardamento caqui, bem como a arma, são elementos de domínio nacional e belicismo, contrastantes com a mensagem pacificadora e de união.

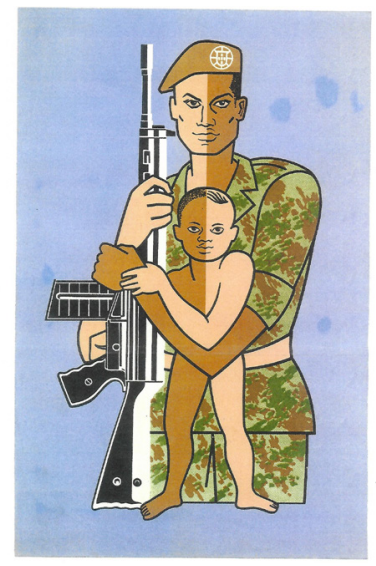

Fig. 1. Cartaz, produzido para a Ação Psicológica do Exército Português, em outubro de 1969. Autoria de Pedro Serra Vaz (Vaz, 2010). 


\section{Fotografar a guerra: o corpo e o retrato}

As fotografias aqui em análise, produzidas no final dos anos 60, início dos anos 70, dão prova da democratização da tecnologia fotográfica nesta época. Era já comum possuir máquinas fotográficas com elevado nível de portabilidade, e fotografar um hábito acessível, o que consubstancia a chamada "Kodak Culture", assumindo a fotografia funções de representação dos momentos chave da vida social. Este processo de generalização da tecnologia tem origem em meados do século XIX, com o desenvolvimento do capitalismo industrial, contemporâneo das primeiras formas de generalização desta tecnologia e do estabelecimento dos usos que inevitavelmente se inscrevem na cultura do médium, de acordo com Mette Sandbye, que especifica as ocasiões que passaram a ser fotográficas:

Podemos falar de uma cultura Kodak global muito associada à sociedade do bem-estar do pós-Segunda Guerra Mundial, em que a câmara, pela primeira vez, se torna uma ferramenta social quotidiana. Ou, pelo menos, um dispositivo técnico que é uma parte integrante das viagens, dos eventos sociais e de outros acontecimentos que marcavam os momentos importantes da história familiar (SANDBYE, 2011, p. 177).

Vários autores abordam a questão dos códigos culturais da fotografia, e a forma como a esta constitui simbolicamente o corpo, considerando as redes específicas de relações em que a representação tem lugar, e os fatores ideológicos que a influenciam, em teses que destacam a emergência (e a persistência) da fotografia burguesa:

Os discursos tradicionais sobre fotografia levam-nos a crer que esta no século XIX constituiu uma democratização do retrato. A fotografia pareceu expandir a função tradicional da reificação cerimonial e exposição que era antes privilégio da aristocracia [...] E embora a liberalização da economia das auto-representações proporcionada pela fotografia tenha possibilitado aqueles que estavam excluídos de participar, simultaneamente catapultou-os para um sistema representacional cuja estrutura, composição, códigos operativos e meios internos de produção de sentido também os amarrou a um sistema discursivo dominante. (LALVANI, 1993, p. 447).

Tomamos como referência, para esta análise, a distinção estabelecida por Allan Sekula, no texto seminal The body and the archive (1988), entre fotografia honorífica e disciplinar. A primeira, das classes burguesas, correspondendo a uma adaptação do retrato pictórico aristocrático, mimetizando poses, luz, enquadramento, utilizada para produção de prestígio e pertença de classe ascendente; a segunda, usada para fins científicos, com intenção de produção de registros e estudos de regularidades relativos a desvios sociais de que o autor destaca a contribuição de Bertillon e Galton, no campo policial, em linhas distintas, que não cabe aqui desenvolver; ou ainda, outro uso disciplinar, o retrato automático que ainda hoje vigora nos documentos de identificação. 
Estas modalidades da fotografia, em particular a disciplinar, relacionam-se com o espírito positivista da época, que enquadra a procura de regularidades na vida social e a instrumentalização de tecnologias para esse fim, no âmbito do que Michel Foucault identificou como o controle da espécie e já não do indivíduo, a biopolítica moderna que gere um novo conceito, a população, e exerce poder através de disciplinas do conhecimento, de acordo com as conhecidas teses do filósofo sobre a relação entre saber e poder. Ao distinguir o regime anterior, o poder soberano, da biopolítica moderna, Foucault esclarece a importância do corpo:

\begin{abstract}
É uma tecnologia que visa portanto não o treinamento individual mas pelo equilíbrio global, algo como uma homeostase: a segurança do conjunto em relação aos seus perigos internos. Logo, uma tecnologia de treinamento oposta a, ou distinta de, uma tecnologia de previdência; uma tecnologia disciplinar que se distingue de uma tecnologia previdenciária ou regulamentadora; uma tecnologia que é mesmo, em ambos os casos, tecnologia do corpo, mas, num caso, trata-se de uma tecnologia em que o corpo é individualizado como organismo dotado de capacidades e, no outro, de uma tecnologia em que os corpos são recolocados nos processos biológicos de conjunto (FOUCAULT, 2005, p.297).
\end{abstract}

As economias visuais, tal como definidas por Deborah Poole (1997), envolvendo indivíduos e tecnologias, sistemas de circulação e sistemas culturais e discursivos, constituem parte integrante do processo definido por Foucault, tanto na mobilização da imagem para áreas do saber relacionadas com o controle social como no seu uso mais comum, construindo áreas de visibilidade e invisibilidade que podem eventualmente constituir hierarquizações de poder e conflitos de afirmação, na negociação dos códigos e das suas conotações. O lastro cultural desses códigos, operacionalizados através de efeitos de formato, pose, luz, adereços, situações, forma aquilo que Sekula denomina como "o arquivo sombra":

Podemos então referir-nos a um arquivo generalizado e diverso, um arquivo sombra, que compreende uma ampla área ao mesmo tempo que nela situa os indivíduos. Este arquivo contém arquivos subordinados, territorializados: arquivos cuja interdependência semântica é normalmente obscurecida pela "coerência" e "mútua exclusividade" dos grupos sociais inscritos em cada um deles" (SEKULA, 1988, p.10).

Interessa-nos, para esta análise, testar a hipótese da prevalência deste arquivo sobre estas imagens, partindo da premissa de Annateresa Fabris de que "as modalidades de representação do indivíduo estabelecidas pelo século XIX permeiam ainda hoje a concepção do retrato, permitindo estabelecer um continuum entre os diversos momentos pelos quais passou a modernidade" (FABRIS, 2004, p.16), ideia que preside à obra em que a autora convoca as teses de Sekula para a sua reflexão sobre a relação entre fotografia e identidade. 
A reflexão fotografia e identidade, nesta linha, pressupõe a natureza social da visão, ou na formulação de Martin Jay (1988), os regimes escópicos que se se instauram em cada época, podendo coexistir mais do que um. Segundo Lalvani, é a perspectiva linear, criada na pintura e replicada mecanicamente no daguerreótipo e na máquina fotográfica, que reforça a dicotomia sujeito (que olha) e objeto (que é olhado), instigando o espectador a assumir a subjectividade do olhar da câmera, tornando o objeto inerte e o sujeito transcendental (LALVANI, 1993, p. 443). Embora admitamos que a questão da perspectiva condicione as dinâmicas representacionais, e se considere, neste trabalho, a influência dos modelos ou regimes discursivos da fotografia burguesa identificados por Allan Sekula, serão tidas em conta outras abordagens teóricas à fotografia, pertinentes para a análise destas imagens.

\section{Fotografar-se na guerra: entre a honra e a domesticidade}

Do retrato honorífico burguês muitas são as marcas patentes na fotografia contemporânea. Annateresa Fabris retoma algumas dessas características, como a pose não frontal e os mecanismos de inscrição num grupo de pertença como, por exemplo, o vestuário e o entorno. Como sublinha a autora, a pose, seja ela mais convencional ou recriadora de circunstâncias de alguma naturalidade social, é uma das formas de significação visual de uma identidade:

Colocar-se em pose significa inscrever-se num sistema simbólico para o qual são igualmente importantes o partido compositivo, a gestualidade corporal e a vestimenta usada para a ocasião. O indivíduo deseja oferecer à objetiva a melhor imagem de si, isto é, uma imagem definida de antemão, a partir de um conjunto de normas, das quais faz parte a percepção de si próprio. Neste contexto, a naturalidade nada mais é do que um ideal cultural, a ser continuamente criado antes de cada tomada (FABRIS, 2004, p.36).

Muitas das imagens produzidas por combatentes portugueses podem ser enquadrados nesta categoria do retrato honorífico, por reproduzirem algumas das convenções que reforçam uma identidade de prestígio, tendo em conta o contexto em que se situam. As figuras 2, 3 e 4 mostram o mesmo militar, sempre ligeiramente de perfil, em todas as situações fardado, um elemento identificador da pertença ao exército português, em três dimensões da experiência de guerra: bélica, carregando uma arma, no meio do mato, claramente em pose para a fotografia (figura 2); em trânsito, num aparelho voador, onde a posição do modelo, igualmente deliberada, favorece o destaque do símbolo na boina, que identifica o ramo do Exército (figura 3); em funções administrativas, concentrado em documentos, numa pose artificialmente natural, num espaço interior que remete para um escritório (figura 4). 


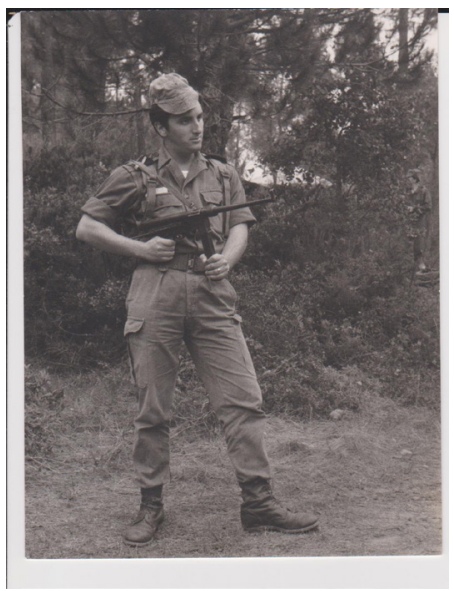

Fig. 2. Arquivo pessoal de Adalberto Melo. Angola, 1971-1973.

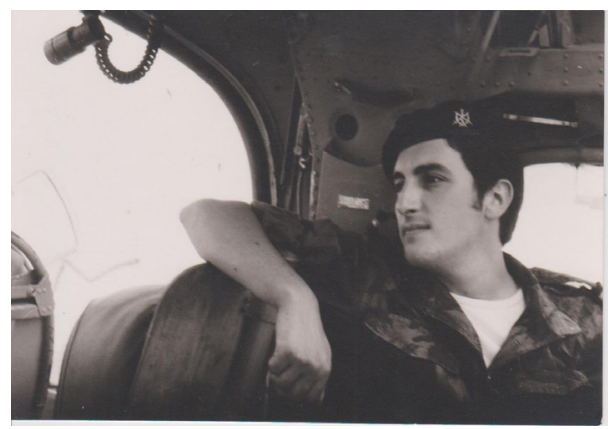

Fig. 3. Arquivo pessoal de Adalberto Melo. Angola, 1971-1973.



Fig. 4. Arquivo pessoal de Adalberto Melo. Angola, 1971-1973.

Em nenhuma destas imagens o retratado olha para a câmara, embora se perceba uma consciência dela, e tanto a pose clara como a simulação de naturalidade, bem como a composição equilibrada das imagens e a integração no enquadramento de um cenário 
definido, correspondem a uma teatralização, bastante idealizada, dos vários aspectos da pertença militar e dos papéis assumidos naquele conflito. Destaca-se que na figura 2, que remete para a dimensão bélica, o retrato é de corpo inteiro, numa representação integral do corpo de risco. Outras imagens têm as mesmas características, de pose dignificante, sem que o retratado encare diretamente a câmara com olhar (figuras 5 e 6) e associando o corpo ao cenário, de forma que este contribui para a composição da identidade em destaque, como é o caso do soldado em pleno mato (figura 6), realidade africana particularmente hostil e desafiante para os combatentes portugueses que enfrentavam guerrilheiros conhecedores do terreno, com estratégias diferenciadas da guerra tradicional.

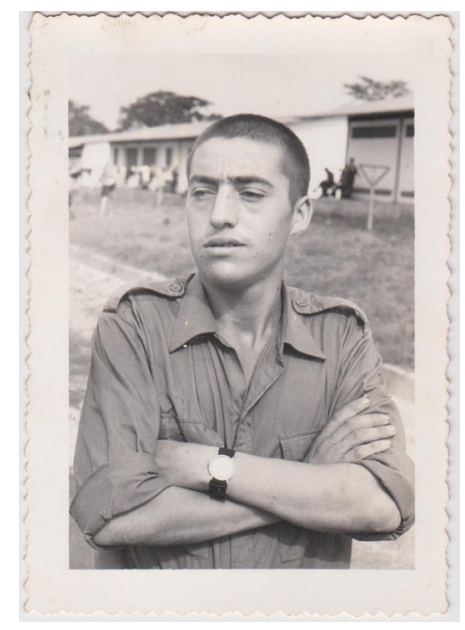

Fig. 5. Arquivo pessoal de Mário Carvalho. Guiné, 1972-1974.

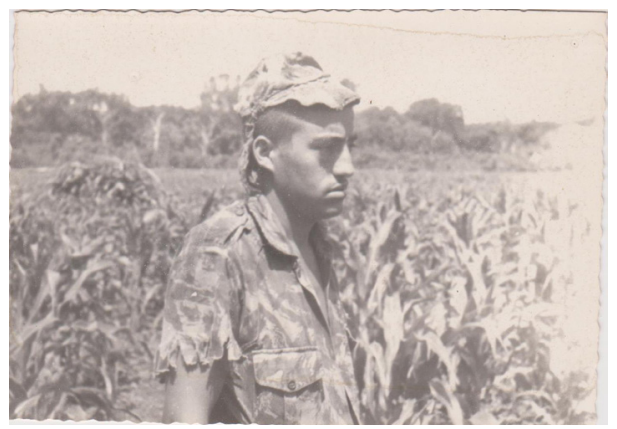

Fig. 6. Arquivo pessoal de Mário Carvalho.Guiné, 1972-1974.

A mesma teatralização da identidade encontra-se noutra fotografia do corpus, podendo-se perceber a preparação da atitude para a produção da fotografia, com forte investimento simbólico, mostrando um soldado, fardado, contemplando uma santa, associando a missão bélica à proteção divina (figura 7). 


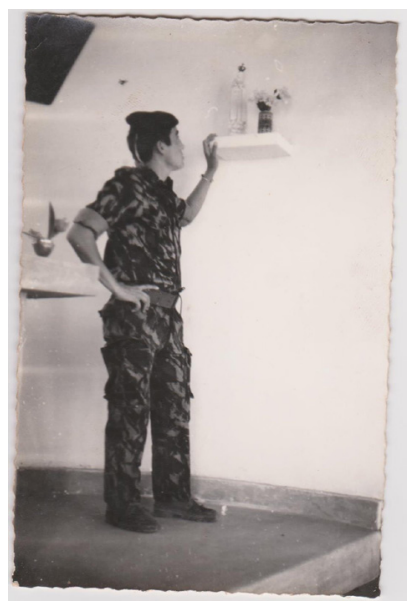

Fig. 7. Arquivo pessoal de Mário Carvalho.Guiné, 1972-1974.

A questão do cenário, no retrato burguês, é reforçada pela prática da fotografia de estúdio, que imprime uma estética ao gênero até à actualidade, como sublinha Fabris:

"[...] o retrato fotográfico é uma afirmação pessoal, moldada pelo processo social no qual o indivíduo está inserido e do qual derivam as diferentes modalidades de representação. Ao folhear os álbuns, o indivíduo é colocado diante de um repertório codificado de atitudes gestuais, que impõem (parecendo sugerir) a pose mais digna, ou seja, a pose mais adequada a atestar a sua posição social (FABRIS, 2004, p. 35).

Um elemento interessante nos retratos analisados é a opção de ser representado junto a animais selvagens (figura 8), em imagens claramente encenadas, num efeito performativo ficcional do domínio do homem sobre a fera, retórica simbolicamente bélica, num contexto em que os guerrilheiros eram caracterizados pelo discurso oficial como criaturas desumanas. Noutra linha, os retratos com animais exóticos surgem também em situações muito semelhantes às do convívio com um animal de estimação nos moldes da cultura europeia então vigente (figura 9).

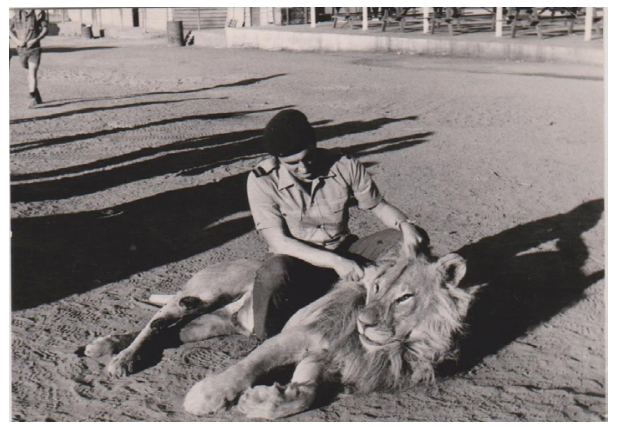

Fig. 8. Arquivo pessoal de Adalberto Melo. Angola, 1971-1973. 


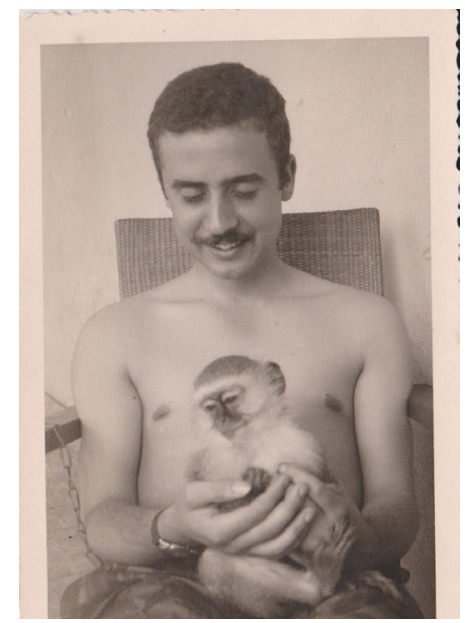

Fig. 9. Arquivo pessoal de Luís Alves. Angola, 1963-1965

Alguns retratos representam assim hábitos da vida, de um contexto deslocado da guerra, mas integrando elementos da paisagem do conflito. Poderemos, então, inseri-los num conjunto de imagens de "domesticidade", nas palavras de Isabel Capeloa Gil:

Para os soldados lidando com a morte eminente na frente de batalha, o lar é o derradeiro modo de auto-identificação, desempenhando as fotos de família o papel de substituto dos entes queridos que estão longe. Da mesma forma, as representações de uma suposta família de companheiros de guerra efectiva uma triangulação do olhar familiar que proporciona um sentido de continuidade em relação à família que ficou em casa (GIL, 2013, p. 40).

Neste conceito inserem-se imagens que retratam o militar em atividades comuns, como tomar banho (figura 10), atividades lúdicas como jogar futebol (figura 11), descansar (figura 12) ou conviver com os amigos à volta de uma mesa (figura 13).

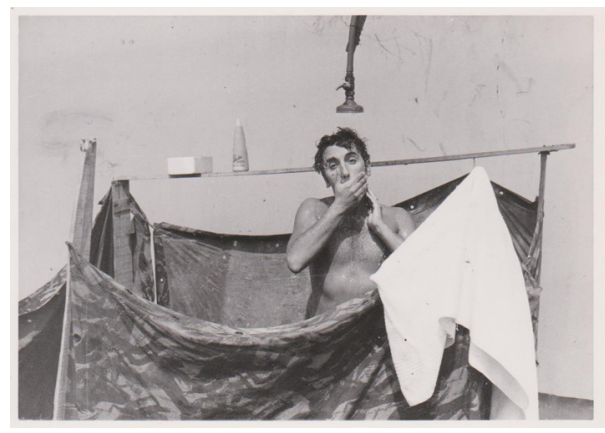

Fig. 10. Arquivo pessoal de Adalberto Melo. Angola, 1971-1973. 


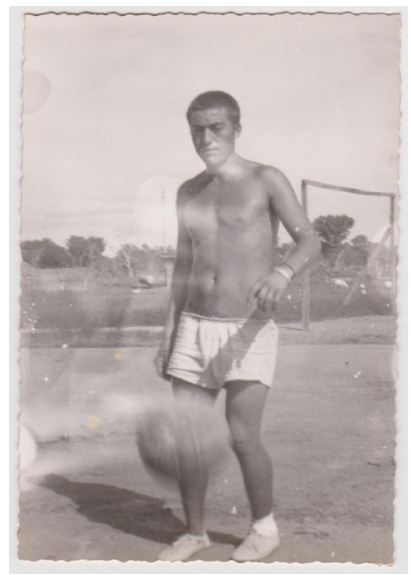

Fig. 11. Arquivo pessoal de Mário Carvalho.Guiné, 1972-1974.

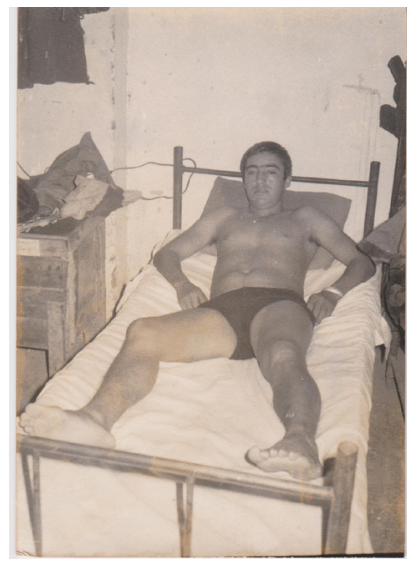

Fig.12. Arquivo pessoal de Mário Carvalho.Guiné, 1972-1974.

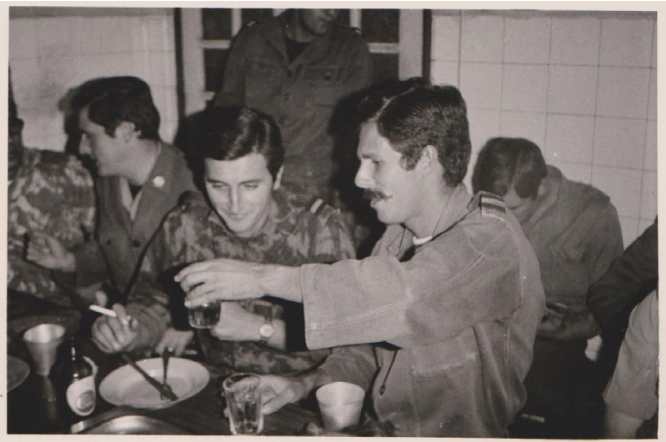

Fig. 13. Arquivo pessoal de Adalberto Melo. Angola, 1971-1973. 
Estas são fotografias onde normalmente os retratados estão vestidos de modo informal ou com pouca roupa, mimetizando um conforto e uma descontração tipicamente doméstica, no sentido da afetividade, rotina e intimidade, associados à vida familiar. Frequentemente este tipo de imagens, produzidas em contexto de guerra, eram enviadas para as famílias ou entes queridos na correspondência postal. No âmbito das relações coloniais, a importância da fotografia situa-se tanto a nível afetivo como a nível cultural, operando um deslocamento do campo de visualização das colônias, como assinala Paul Landau, referindo-se às imagens dos primeiros viajantes a África:

\begin{abstract}
Nesse tipo de visibilidade das viagens ${ }^{3}$, a fotografia transferiu "a localização da análise" dos lugares distantes para o conforto da classe media do Ocidente. Ao contrário do que acontecia com "exposições" e museus, no entanto, as fotografias eram posse individual. Postais, revistas, pacotes de tabaco, livros de caçadores e narrativas de viagem ilustradas, todos estes formatos, faziam chegar a mensagem na segurança das salas de estar e estúdios urbanos. A transição da pintura para a reprodução mecânica, entre outras implicações, claramente causou uma transição da exibição pública para o visionamento privado (LANDAU, 2002b: 145).
\end{abstract}

\title{
Retrato disciplinar: campo de poder e contestação
}

No corpus em análise, encontram-se algumas fotografias da população local. Em registro de retrato, individualizado ou destacado, são sobretudo imagens de mulheres. Representam nativas, que os militares encontravam nas aldeias, encarando, na maior parte dos casos, a câmara de forma frontal. Como esclarece Fabris, na tradição do retrato, a pose frontal mais rígida ocupa um lugar na hierarquização social da representação, correspondendo ao inferior "homem natural" por oposição a uma postura mais "afetadamente lateral" do superior homem civilizado (FABRIS, 2004, p.35).

A associação entre os locais e um estado natural não civilizado é reforçada pela ideia então dominante sobre as populações africanas, ditas primitivas, detentoras de uma cultura inferior e beneficiárias dos referentes cristãos e europeus da colonização, numa dependência identitária sintetizada assim por Paul Landau: “O 'selvagem africano' é o gémeo não explicitado do 'homem super civilizado”" (LANDAU, 2002a, p.5).

A prática fotográfica enquanto fenômeno cultural não está imune ao sistema de valores e referentes sociais referidos, e ambos se alimentam mutuamente. Lalvani aborda especificamente o impacto desta interacção a nível das representações diferenciadas do corpo:

O olhar frontal nestes casos deveria ser lido em contraste directo com as assimetrias cultivadas pela pose aristocrática, pois a pose é uma função de lazer, e a frontalidade significa a sua ausência. O lazer ou o que este implica em termos de liberdade da reprodução do corpo torna possível não apenas o seu uso notório mas a sua representação como texto simbólico (LALVANI, 2006, p. 449).

3 O autor refere-se a publicações que já incluíam imagens fotográficas dos territórios e povos africanos, bem como exposições e museus com imagens coloniais. 
No corpus analisado, a questão da representação do aspecto selvagem dos nativos reiterada através de convenções fotográficas encontra-se, por exemplo, em três imagens de mulheres (figura 14, 15 e 16) que apresentam declarada frontalidade e uma nudez estranha aos costumes europeus. A produção de uma relação directa e, pode supor-se, subjugada ao olhar por trás da objectiva, parece colocar estes retratos na categoria das imagens disciplinares, estando em causa relações de poder, neste caso, em contexto colonial. Acresce que o elemento da nudez, no caso dos dois retratos de mulheres jovens (figuras 14 e 16), constitui um fator de erotização para um português da época, contextualizado num ambiente social de grande censura em relação ao sexo. São imagens com algum aspecto predatório, desde logo pela relação dominante do masculino sobre o feminino, particularmente evidente na imagem em que se pode ver os soldados posando lado a lado com a mulher desnuda (figura 16). O fato de estas mulheres não partilharem o código de sexualização do seu corpo por descobrimento da pele e dos seios implica um grau de violência simbólica.

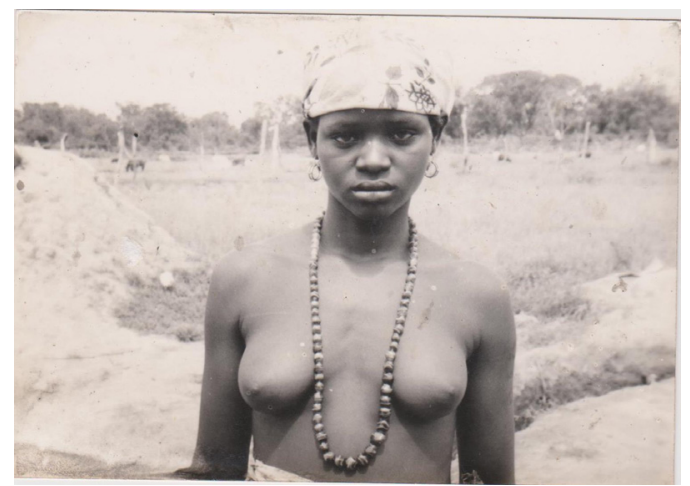

Fig. 14. Arquivo pessoal de Mário Carvalho.Guiné, 1972-1974.

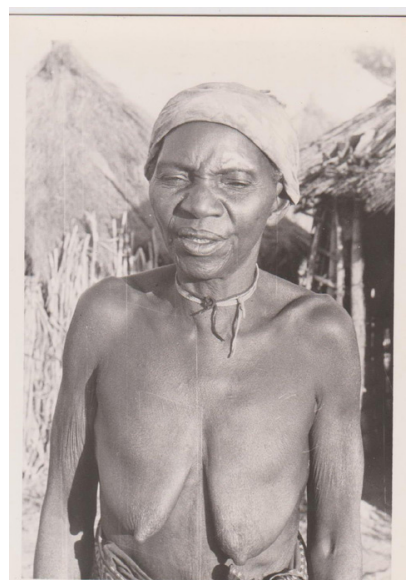

Fig. 15. Arquivo pessoal de Adalberto Melo. Angola, 1971-1973. 


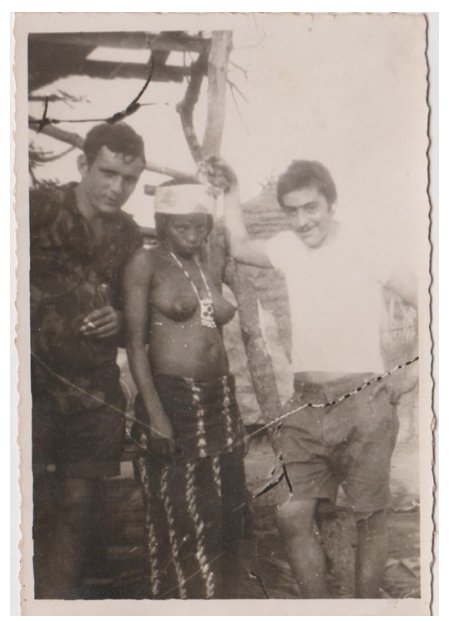

Fig. 16. Arquivo pessoal de Mário Carvalho.Guiné, 1972-1974.

Outro nível de análise da fetichização da nudez feminina remete para o fascínio pelo exótico, e suas conotações, aspecto associado a um imaginário construído de forma altamente hierarquizante, desde o século XIX, e em que as imagens tiveram um papel fundamental. O discurso visual complementava de certa forma o discurso científico, através de representações essencialistas e infantilizantes, reiterando e justificando relações de domínio, o que nos remete para a teorização de Michel Foucault que articula poder e conhecimento. Laudau refere-se a essa construção de diferenciações e distâncias:

\begin{abstract}
Da mesma forma que as identidades africanas foram essencializadas de acordo com a imagem de África esboçada pelas representações em papel, uma ciência dos corpos e das raças tornou-se uma referência dos argumentos biológicos sobre a inferioridade Africana. A "espantosa distância" tornou-se um hiato cronológico: os africanos viviam numa era passada, que ficou acidentalmente perdida no presente (LANDAU, 2002a, p.4).
\end{abstract}

O desenvolvimento dos saberes coloniais surgiu com a necessidade das potências europeias sedimentarem os seus domínios territoriais, sobretudo a partir da Conferência de Berlim, conforme explica Patrícia Ferraz Matos (MATOS, 2006, p. 56), o que causa a sistematização de estudos essencialmente classificatórios sobre as populações, vertidos para formas culturais acessíveis e de ampla divulgação, como publicações ou exposições coloniais. Clara Carvalho sublinha, na esteira de Landau, o papel da fotografia no reforço da hierarquização de culturas, assimiladas a raças, pelas disciplinas e subprodutos de divulgação cultural e científica na passagem do século XIX para o XX: 
Foram exacerbadas as diferenças físicas, e, sobretudo, de vestuário ou ornamentação que permitissem criar tipos ou "tribos", na definição utilizada na época. Os indivíduos fotografados ou expostos eram exemplo da diferença, obrigados a representar realidades sociais consideradas inferiores, em termos materiais e morais. Como tal, privilegiavam-se os elementos que podiam expor essa distância considerada significativa: o vestuário simples, denotando poucos meios tecnológicos e a exposição de uma quase nudez. A empresa colonial justificava-se pela necessidade de "civilizar", "ensinar" e "moralizar" os sujeitos da colonização (CARVALHO, 2008, p.147-148).

No caso português, as diferenciações cultivadas por estes saberes inscreveram-se desde logo na legislação do Estado Novo (1926-1974), com a criação do Estatuto do Indígena, em 1930, e as diversas variações deste ao longo dos anos que, mesmo quando da supressão do documento original, mantêm as distinções de direitos e deveres entre população branca e negra, com explicitação desse aspecto fisionômico. O corpo, enquanto símbolo da pertença cultural, esteve sempre inscrito no projeto colonial português: "Embora vinculados a uma mesma nacionalidade as muitas sociedades que habitavam o império eram designadas por 'raças"' (MATOS, 2006, p. 63). Basta recordar que o estatuto de assimilado, com direitos mais próximos dos cidadãos metropolitanos, dependia do abandono dos costumes da raça negra (MATOS, 2006, p. 63).

Raça e gênero associam-se, neste quadro, enquanto critério de subjugação. No que diz respeito ao lastro da representação fotográfica das mulheres negras em particular, em publicações de divulgação cultural, Clara de Carvalho assinala: "A mensagem que parece exposta nestas representações é clara: nas colônias africanas há seres exóticos e entre estas populações existem primitivos que apelam a sentimentos recalcados de sedução e posse" (CARVALHO, 2008, p. 154). Outra investigadora com obra sobre a representação colonial das mulheres no império português, Filipa Lowdes Vicente, destaca a oposição deste tipo de imagens em relação à norma honorífica: "As desigualdades e as assimetrias de poder indissociáveis do colonialismo vieram colocar o corpo da mulher não ocidental num lugar de fronteiras mais indefinidas e numa visibilidade mais legítima' (VICENTE, 2012, p. 446). A exposição da nudez alheia através da fixação de um olhar predatório coincidem, assim, com uma tradição imagética socialmente sedimentada.

Duas outras imagens, uma de mulher (figura 17), de aparência idosa, fumando enquanto apanha galhos do chão, e de uma pessoa de gênero indeterminado, presumivelmente masculino por se tratar de um protagonista de um ritual (figura 18), inserem-se também numa linhagem imagética centrada no exótico, na ancestralidade e na essência pré-colonial. 


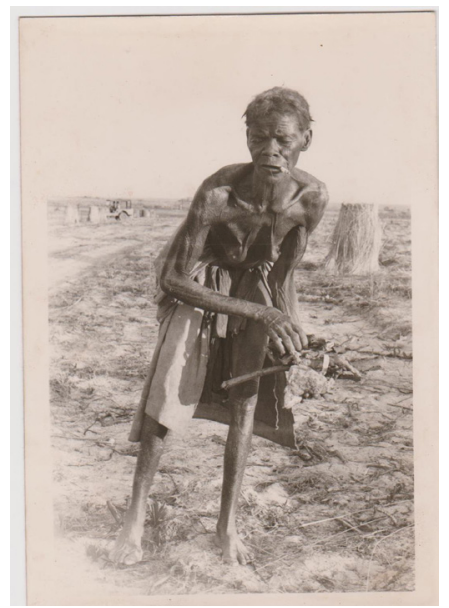

Fig. 17. Arquivo pessoal de Adalberto Melo. Angola, 1971-1973.

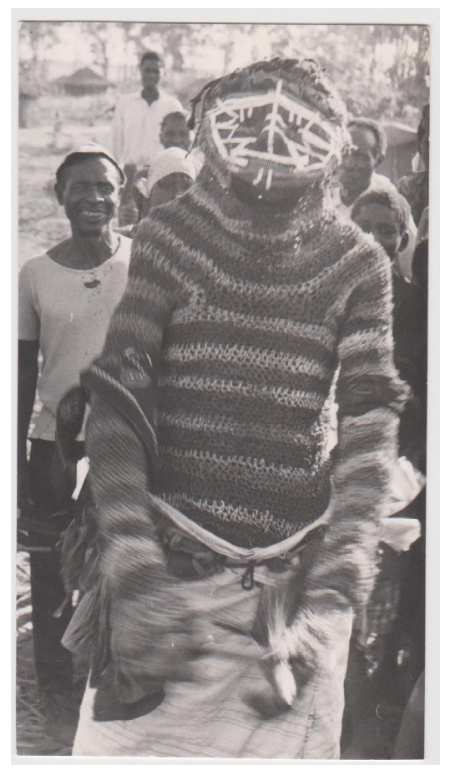

Fig.18. Arquivo pessoal de Adalberto Melo. Angola, 1971-1973.

É assinalável que estas fotografias não cumpram a rigidez frontal da fotografia disciplinar, revelando não só a influência do imaginário colonialista mas também, eventualmente, os sinais de uma mudança no próprio discurso visual vigente. Tomamos por referência o estudo de Clara de Carvalho sobre as imagens do Boletim Cultural da Guiné, o principal órgão do governo daquela colônia, uma publicação que se inicia em 1946 
e segue até 1973 (CARVALHO, 2008, p.157). A autora identifica regularidades no padrão representacional das imagens, que começa por ser dedicado à categorização e tipologização, na esteira da visualidade científica, passando a uma linha que incluía visitas oficiais à colônia, reportagens de missões técnicas, nunca perdendo uma vertente etnográfica, culminando numa política particular no tempo de guerra, sem nunca referir o conflito em curso:

Contudo a partir dos anos 60, procuram-se publicar de forma mais sistemática as fotografias que representavam sujeitos em interação com o fotógrafo. Multiplicamse as fotografias de régulos e dos seus familiares, com os quais, desde finais da década de 60 , se procuram estabelecer novas pontes de contato, visando o controle das populações locais" (CARVALHO, 2008, p.161).

A visualidade científica e a de propaganda, fatores impossíveis de ignorar no contexto cultural destes fotógrafos amadores, coincide com a hipótese levantada por Isabel Capeloa Gil sobre aquilo que designa por "espetáculo do Outro colonial", identificando três padrões: exotismo e distanciamento, educação biopolítica e aniquilação simbólica. No entanto, a autora salvaguarda possibilidades de contestação dos regimes visuais hegemônicos:

Apesar disso, no âmbito do enquadramento fotográfico e tecnológico, atira-se simbolicamente contra o colonizado mas, defenderia, ele nem sempre morre. Ao mesmo tempo que a fotografia colonial inventa (um) Outro, também revela a subjectividade escondida por trás da câmara. Embora esta replique as relações de poder da lógica colonial, por a máquina simbolicamente dominar o objecto, a fotografia permite tanto ao colonizado como ao seu senhor estabelecerem um diálogo que ultrapassa a economia do enquadramento (GIL, 2014, 23).

Podemos observar um exemplo desse nível de negociação por parte dos subjugados a um determinado regime visual e à própria inacessibilidade da tecnologia, numa imagem particular (figura 19), em que a mulher retratada, liberta de uma pose frontal, semi-nua, coloca uma blusa sobre o seu corpo, fixando-se na fotografia a transição entre corpo descoberto e tapado, assinalando possivelmente uma recusa da fetichização do seu corpo.

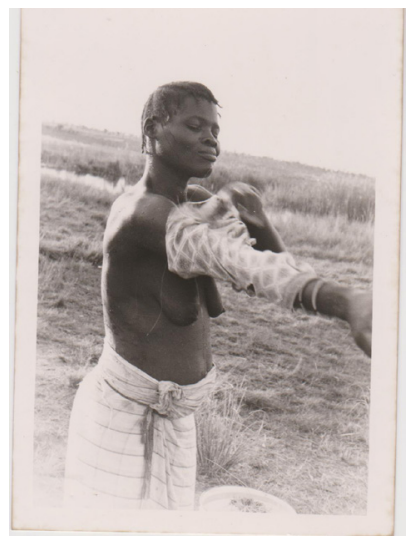

Fig.19. Arquivo pessoal de Adalberto Melo. Angola, 1971-1973. 
Marie Louise Pratt refere este fenômeno, no campo literário, extrapolável para o campo visual, evocando precisamente o regime hegemônico dominado pelos saberes coloniais e referindo-se à "auto-etnografia: "Uso este termo para me referir a instâncias em que os sujeitos colonizados empreendem a sua própria representação de formas que se relacionam com os termos dos colonizadores" (PRATT, 1992, p. 7). Trata-se de considerar, no caso do retrato, a contribuição do próprio retratado para a sua representação, numa dialética social que oscila entre o individual e o grupal, as convenções ideológicas e o gesto pessoal. No campo fotográfico, falamos de uma negociação de poder no campo do olhar, de quem olha e de quem é visto, nem sempre igualitária, e em contexto colonial, muito pouco, mas ainda assim possível: "O retrato, de fato, ativa um mecanismo cultural que faz o indivíduo alcançar a própria identidade graças ao olhar do outro" (FABRIS, 2004, p. 51).

Outras nuances devem ser consideradas na análise deste corpus, mesmo partindo da caracterização de um regime óptico dominante. Sem dúvida que as idiossincrasias de cada fotógrafo interferem nas representações produzidas, desde a sua sensibilidade estética, posicionamento político e nível de consciência dos mecanismos culturais envolventes. Em contexto colonial, a economia visual integra a influência das circunstâncias ideológicas, tecnológicas e culturais, na constituição de uma representação em circulação sobre povos e poderes, mas também a interferência da singularidade, conforme sublinha Poole: "Cada individuo e imagem constitui uma instância particular no amplo quadro de práticas e discursos representacionais identificáveis" (POOLE, 1997, p. 9-10).

São disso exemplo algumas imagens com certo grau de comicidade, produzida por uma ridicularização induzida e registada, como a imagem de um soldado com um chapéu desadequado à temperatura local, com mulheres ao fundo trabalhando, numa atitude de auto-ironia sobre a sua presença naquele local (figura 20). Ou ainda outra imagem de um militar semi-fantasiado, com um lenço à cabeça, num ambiente íntimo (figura 21), ambas contrárias à simbologia de uma missão civilizadora e bélica, marcada por superioridade civilizacional e dramatismo patriótico.

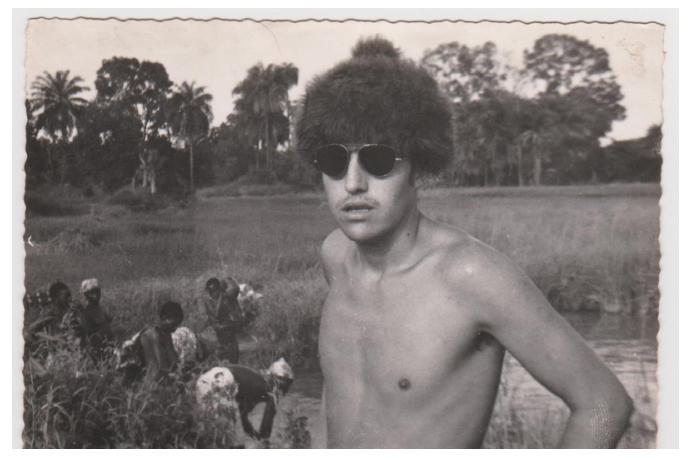

Fig. 20. Arquivo pessoal de Mário Carvalho.Guiné, 1972-1974. 


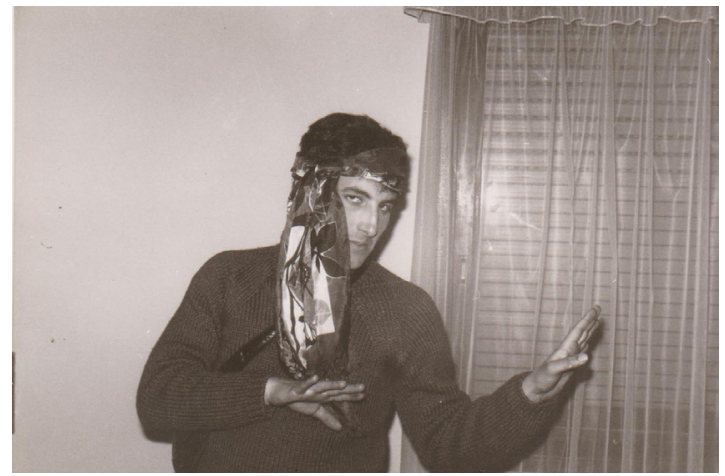

Fig. 21. Arquivo pessoal de Adalberto Melo. Angola, 1971-1973.

Por fim, neste corpus encontram-se representações da alteridade colonial que, ao invés de integrarem as marcas do retrato disciplinar, exibem traços do retrato honorífico, como olhar não intrusivo de carácter contemplativo, assinalado pela distância focal, consequentes naturalidade e ausência de rigidez frontal do modelo e valorização do cenário no enquadramento (figuras 22, 23 e 24). Um retrato é paradigmático e deve ser destacado (figura 25): mostra um homem negro, sério, de perfil, olhando de forma concentrada em frente, ao volante de uma viatura, fumando. Trata-se de uma representação que destaca a individualidade do retratado, na caracterização plena da sua negritude pelo plano aproximado, deixando ver a sua competência numa tarefa que requer perícia e formação, e tendo no cigarro uma marca estética típica da masculinidade normativa da época.

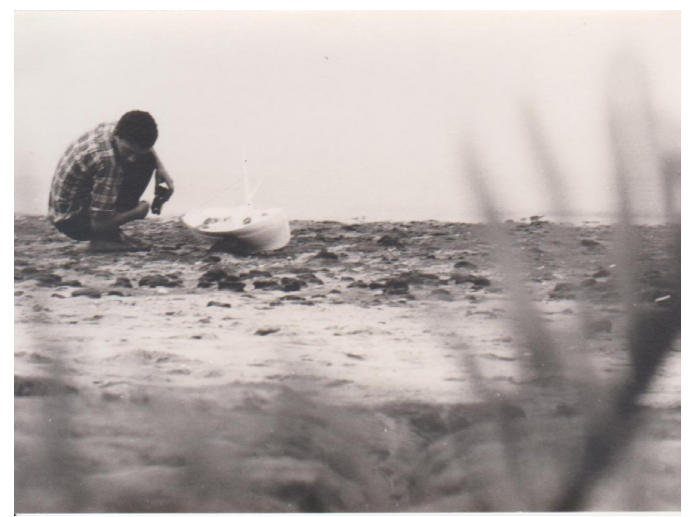

Fig. 22. Arquivo pessoal de Adalberto Melo. Angola, 1971-1973. 


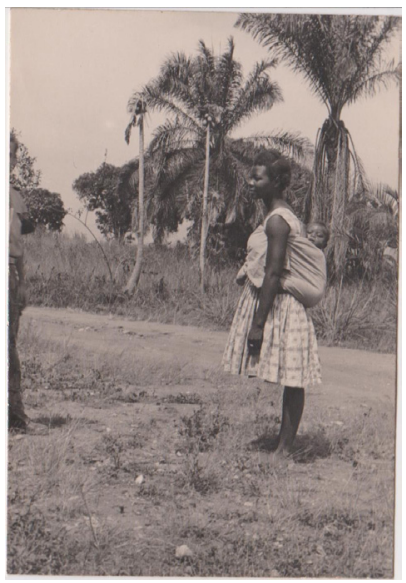

Fig. 23. Arquivo pessoal de Luís Alves. Angola, 1963-1965.

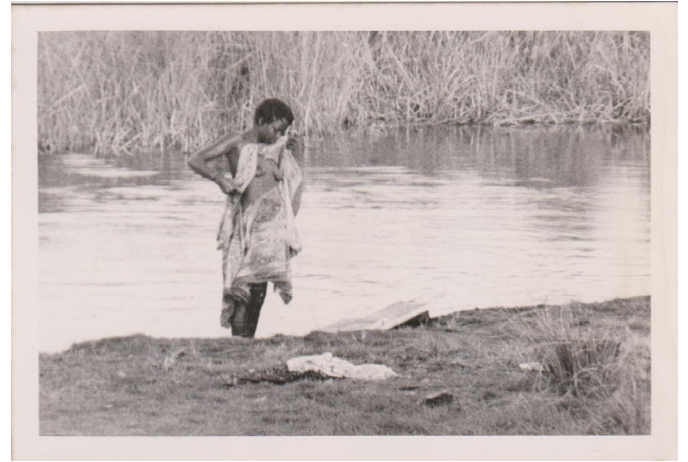

Fig. 24. Arquivo pessoal de Adalberto Melo. Angola, 1971-1973.

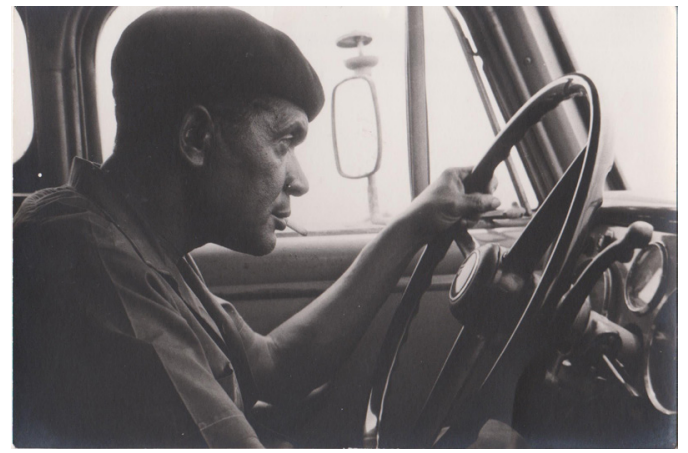

Fig. 25. Arquivo pessoal de Adalberto Melo. Angola, 1971-1973. 


\title{
Notas conclusivas: a cidadania fotográfica e a memória
}

A análise dos retratos produzidos por militares portugueses durante a guerra colonial partiu da hipótese de que as convenções fotográficas honoríficas e disciplinares poderiam enquadrar estas representações, absorvendo elementos de uma forte tradição imagética sobre o colonialismo. No entanto, além deste fator, verificado em muitas imagens, observaram-se possibilidades de resistência à suposta hegemonia dessas convenções. Exemplos disso estão patentes no olhar diverso, e por vezes honorífico, sobre a alteridade cultural e étnica, bem como em certos elementos atípicos de auto-representação.

Imagens da guerra colonial portuguesa são hoje lastros de um conflito que marcou uma profunda mudança de paradigma político, ideológico, cultural e social. Portugal fez uma transição democrática, procedeu à descolonização e retirou-se dos cenários de guerra, sendo as ex-colónias estados independentes desde 1975. A herança desse passado pulsa hoje nos fluxos migratórios decorrentes, na constituição de relações conviviais ou hostis, em questões diplomáticas, na relação de Portugal com uma identidade que passou de uma dimensão transcontinental a um pequeno estado da União Europeia. Trata-se de um processo cuja memória é, pois, de importância central para os desafios da atualidade, constituindo estas imagens campos de visualidade não apenas históricos mas contemporâneos, na medida em que a memória é sempre um exercício presente de rearticulação e negociação de sentidos.

Nesse sentido, considera-se incontornável o contributo de Ariella Azoulay para esta reflexão, pois o conceito que propõe de cidadania fotográfica convoca precisamente uma tríade que inclui fotógrafo, fotografado e, defendemos, o protagonista da memória: o espectador.

\begin{abstract}
Ao longo do tempo, tornou-se progressivamente mais claro para mim não só que é impossível reduzir a fotografia ao seu papel de produtora de imagens mas também, além disso, que a sua ampla disseminação na segunda metade do século XIX criou um espaço de relações políticas que não são mediadas exclusivamente pelo poder do estado e não totalmente sujeitas a lógicas nacionais que ainda ofuscam a arena política conhecida. Este espaço cívico político, que criei teoricamente neste livro, é aquele que as pessoas que usam a fotografia - fotógrafos, espectactores e fotografados —imaginam todos os dias (AZOULAY, 2008, p.11).
\end{abstract}

Assim entendido, o "espaço cívico político" instaurado por imagem, é constituído em grande parte pela sua dimensão testemunhal, presente no aspecto indexical da fotografia (como celebrizado pela afirmação de Roland Barthes (2012) de que esta constitui um lastro de fotógrafo e fotografado terem estado ali), mas também pelo olhar do espectador, sendo impossível fixar significados sem considerar o contrato informal, ético, transnacional e atemporal que esta relação tríplice estabelece.

Embora seja mais fácil conceber esta relação em imagens de imprensa ou, 
actualmente, naquelas divulgadas na internet, também se aplica aos arquivos privados da era analógica, frequentemente partilhados em família, entre amigos, deixados a herdeiros ou facultados a uma investigação: "A fotografia está aí, em todo o lado, um objecto no mundo, e qualquer pessoas, sempre (pelo menos em princípio) pode puxar um dos seus fios e manuseá-lo de tal forma que reabre e renegocia o que a fotografia mostra, possivelmente até perturbando completamente o que era visto antes" (AZOULAY, 2008 p. 13).

Na multiplicidade, praticamente infinita, defendemos, aberta por esta abordagem, é que reside a performatividade hermenêutica da cidadania fotográfica. Se estes retratos constituem representações de corpos concretos de guerra, a fluidez da temporalidade em que se inscrevem cria desafios ao modo como se pensa hoje o passado colonial, face às identidades reconfiguradas no presente. Como escreve Fabris, sobre fotografia e memória:

Perpetuação da memória. Instabilidade da memória. Essas duas possibilidades encerram, se não todas, pelo menos algumas das questões centrais colocadas pela fotografia, a qual herda da imagem tout court o papel de mediadora entre diferentes esferas da vida social igualmente interessadas em dar um sentido para a passagem do tempo e a sua relação com a memória (FABRIS, 2016, p.55).

Clara Roldão Pinto Caldeira cursa o doutoramento em Estudos de Cultura na Universidade Católica Portuguesa (The Lisbon Consortium) em duplo grau com a PUC-Rio. É formada em Ciências da Comunicação pela Universidade Nova de Lisboa, com mestrado em Jornalismo. Trabalhou como jornalista na área cultural em televisão, produtora e gestora de conteúdos online e tradutora freelancer. Desenvolve a tese "Fotografia da Guerra Colonial Portuguesa: memórias visuais", refletindo obre a relação entre fotografia e memória, analisando imagens de imprensa da época e arquivos privados de ex-combatentes portugueses.

clara.caldeira@gmail.com

\section{Referências}

ALVES, T. O sentido fabricado do início da guerra em Angola na imprensa de Lisboa. In: TORRES, S. (Org.). O Jornalismo Português e a Guerra Colonial, Lisboa: Guerra e Paz, pp. 61-86, 2016.

AZOULAY, A. The Civil Contract of Photography. Nova lorque: Zone Books, 2008.

BARTHES, Roland. A Câmara Clara. Lisboa: Edições 70, 2012 [1980].

CARVALHO, C. "Raça" e Género na Imagem Colonial: Representações de Mulheres nos Arquivos Fotográficos. In: PAIS, J.M.: CARVALHO, C.: GUSMÃO, N. (Orgs.). O Visual e o Quotidiano, Lisboa: Imprensa de Ciências Sociais, pp. 145-174, 2008.

CASTELO, CLÁUDIA; "O Modo Português de Estar no Mundo". In: O luso-tropicalismo e a ideologia 
colonial portuguesa (1933-1961). Lisboa: Edições Afrontamento, 2011.

FABRIS, A. Identidades Virtuais. Uma leitura do retrato fotográfico. Belo Horizonte: Editora UFMJ, 2004.

Fotografia e memória: teses em confronto. In: CORNELSON, E.L.: VIEIRA, E.A.: QUIJADA, G.L. (Orgs.). Em torno da imagem e da memória. Rio de Janeiro: Jaguatirica, p. 35-56, 2016.

FOUCAULT, M. Aula de 17 Março de 1976. Em Defesa da Sociedade. Curso no Collège de France (19751978); Tradução de Maria Ermantina Galvão. São Paulo: Livraria Martins Fontes Editora, 2005 [1980].

GIL, I.C. Framing war: Domesticity and the visuality of Conflict. In: SPELL : Swiss papers in English language and literature. Zurique, Vol 29, p.31-49, 2013.

Visual Recall in the Present. Critical nostalgia and the Memory of Empire in Portuguese Culture. In: SEGAL, M.:, Daniela KOLEVA, D. (Orgs.). Cultural Literacy in Europe, Londres: Palgrave, pp. 25-52, 2014.

JAY, M. The scopic regimes of modernity. In: FOSTER, H. (Org.). Vision and Visuality, Seatle: Bay Press, p. 3-28, 1988.

LALVANI, S. Photography, epistemology and the body. In: Cultural Studies, Vol.7, issue 3, p. 442-465, 1993.

LANDAU, P. Empires and the Visual: Photography and Colonial Administration in Africa. In: LANDAU, P.S.: KASPIN, D. (Orgs.). Images and Empires. Visuality in Colonial and Postcolonial Africa. Berkeley, Los Angeles, Londres: University of California Press, p.1-40, 2002a

. Introduction: An Amazing Distance: Pictures and People in Africa. In: LANDAU, P.S.: KASPIN, D. (Orgs.). Images and Empires. Visuality in Colonial and Postcolonial Africa. Berkeley, Los Angeles, Londres: University of California Press, p.141-171, 2002b

MATOS, P. F. As Cores do Império. Representações Raciais no Império Colonial Português. Lisboa: Imprensa de Ciências Sociais, Instituto de Ciências Sociais da Universidade de Lisboa, 2006.

PRATT, M. L. Imperial Eyes. Travel Writing and Transculturation. Londres e Nova lorque: Routledge, 1992.

PIMENTEL, I. 50 anos depois do início das guerras coloniais, alguns dados para avivar a memória. In: Blogue Jugular, 16 março 2011. Disponível em <http://jugular.blogs.sapo.pt/2535614.html> Acesso em: 2 dez 2018.

POOLE, D. Vision, Race and Modernity: A Visual Economy of the Andean Image World, Princeton, New Jersey: Princeton University Press, 1997.

RAMOS, A.D. Angola, 1961: o horror das imagens. In: VICENTE, F. (Org.) O império da Visão. Fotografia no Contexto Colonial Português. Lisboa: Edições 70, pp. 399-435, 2014.

SANDBYE, M. Emotive Templates: The family photo album and its presentation of the good life. In: SIMONSEN, D. G.; VYFF, I. (Orgs.). Amerika og det gode liv. Materiel kultur i Skandinavien i 1950'erne og 1960'erne. Odense: Syddansk Universitetsforlag, p. 173-194, 2011.

SEKULA, A. The body and the archive. October. Nova lorque: The MIT Press, Vol 39, Inverno, p.3-64, 1986.

VAZ, P.S. Uma experiência de Guerra - Angola 68/70. Histórias da C.Caç. 2335. Lisboa: edição de autor, 2010

VICENTE, F. Fotografia e colonialismo: para lá do visível. In: JERÓNIMO, M.B. (Org.), O Império Colonial em Questão (Sécs. XIX-XX). Poderes, Saberes e Instituições. Lisboa: Edições 70, pp. 423-453, 2012 